\title{
Comparison of Cardiovascular Response during Induction of General Anaesthesia Using Etomidate Versus Using Propofol under Bispectral Index Guidance in a Tertiary Care Medical College, Dibrugarh
}

\author{
Utpal Dutta ${ }^{1}$, Shahbaz Bin Sabir², Rituparna Bora ${ }^{3}$ \\ 1,2 Department of Anaesthesiology, Assam Medical College and Hospital, Assam, India, \\ ${ }^{3}$ Department of Physiology, Assam Medical College and Hospital, Assam, India.
}

\section{ABSTRACT}

\section{BACKGROUND}

The present study was done to compare the cardiovascular responses of etomidate and propofol as induction agents of general anaesthesia under Bispectral index (BIS) guidance and evaluate the effect of intravenous induction agent etomidate and propofol on the variation in heart rate and blood pressure during induction of general anaesthesia.

\section{METHODS}

This is a prospective randomized and double blinded comparative study done in Assam Medical College and Hospital on patients scheduled for elective surgeries under general anaesthesia from June 2019 to May 2020. 80 patients were randomly allocated to group E (etomidate group) and group P (propofol group) of 40 each. All patients were pre-medicated with fentanyl 2 microgram / kg intravenously. Group E received etomidate infusion at $0.05 \mathrm{mg} / \mathrm{kg} / \mathrm{min}$ and group P received propofol infusion at $0.5 \mathrm{mg} / \mathrm{kg} / \mathrm{min}$ until Bispectral index value dropped to 60. Patients were intubated with vecuronium $0.1 \mathrm{mg} / \mathrm{kg}$ and maintenance of anaesthesia was continued according to institutional protocol. At the end of anaesthetic period, extubation was done after acceptable recovery. Haemodynamic parameters were recorded in both the groups until 10 minutes of induction.

\section{RESULTS}

Statistically significant fall in heart rate was seen in group $P$ than that of group $E$ starting from 3 minutes of induction up to 10 minutes with $\mathrm{P}$ value $<0.05$ and statistically significant fall in systolic, diastolic, and mean arterial pressure (MAP) was seen in propofol group from that of etomidate group starting from 1 minute of induction up to 10 minutes was seen.

\section{CONCLUSIONS}

We conclude that etomidate is haemodynamically more stable than propofol during the time of induction of anaesthesia.

\section{KEY WORDS}

Etomidate, Propofol, Bispectral Index
Corresponding Author: Dr. Rituparna Bora, Department of Physiology, Assam Medical College and Hospital, Dibrugarh, Assam - 786002, India. E-mail: rituparnadutta6@gmail.com

DOI: $10.14260 / \mathrm{jemds} / 2021 / 541$

How to Cite This Article:

Dutta U, Sabir SB, Bora R. Comparison of cardiovascular response during induction of general anaesthesia using etomidate versus using propofol under bispectral index guidance in a tertiary care medical college, Dibrugarh. J Evolution Med Dent Sci 2021;10(32):2645-2651, 10.14260/jemds/2021/541 DOI:

Submission 10-04-2021,

Peer Review 12-05-2021,

Acceptance 06-06-2021,

Published 09-08-2021.

Copyright (C) 2021 Utpal Dutta et al. This is an open access article distributed under Creative Commons Attribution License [Attribution 4.0 International (CC BY 4.0)] 


\section{BACKGROUND}

The haemodynamic instability and the exaggerated strain response of intubation has made induction of general anaesthesia in patients undergoing surgery a challenging task. Myocardial oxygen demand and supply balance is therefore essential in these patients while inducing anaesthesia. A successful induction of general anaesthesia is when it ensures stability towards haemodynamics along with production of hypnosis. ${ }^{1}$

Since the introduction of general anaesthesia, no ideal substance for ideal induction has been discovered which provides stability in the haemodynamic status during induction of general anaesthesia and after endotracheal intubation. Thiopentone, midazolam, propofol and etomidate have been used as inducing agents to anesthetised patients. Among all these substances, etomidate and propofol are greatly preferred as inducing agents of general anaesthesia for patients undergoing surgery.

This study was undertaken to observe and analyse the haemodynamic response of propofol in comparison with that of etomidate for use in induction of anaesthesia under Bispectral index guidance.

Propofol, an alkylphenol derivative, provides rapid onset of action, antiemesis properties, potent attenuation of pharyngeal, laryngeal, tracheal reflexes and adequate depth of anaesthesia during intubation. It provides short duration of action and clear and smooth recovery.2,3,4 But high dose can cause hypotension due to direct myocardial depression and increased peripheral vasodilation with veno-dilatation, respiratory depression or apnea. ${ }^{5}$ Propofol also causes pain on injection.

Etomidate is chemically a carboxylated imidazole containing drug with rapid onset of action. It's duration of action is also brief. Minimal hemodynamic changes or respiratory depression with cerebral protective effects have been associated with this drug. ${ }^{6}$

The effect of etomidate on the cardiac output and oxygenation of myocardium along with its wider therapeutic index is believed to be six times more than thiopentone and propofol. Thus, it has seen to be used in patients of all age groups. Some of the side effects are pain on injection, thrombophlebitis, and myoclonus.

Now a proper assessment of depth of anaesthesia is fundamental to anaesthesia practice. ${ }^{7}$ Selecting an appropriate supervision method to assess the anaesthetic depth will guide to optimize the amount of drug delivery. It also reduces the cost and improves the outcome of surgery. ${ }^{8}$ Bispectral index is one of the monitoring methods that can directly assess the effects of an anaesthetic agent on analgesia and hypnosis during surgery which helps the anaesthesiologist to derive the satisfactory effects of the anaesthetic drugs and decrease the adverse cardiopulmonary effects. ${ }^{9}$ In view of the above, we proposed to conduct this comparative randomized study.

The objective of this study was to evaluate the effect of intravenous induction agent etomidate and propofol on the variation in heart rate and blood pressure during induction of general anaesthesia under Bispectral guidance.

\section{METHODS}

This is a prospective randomized and double blinded comparative study. Patients scheduled for elective surgeries under general anaesthesia in Assam Medical College and Hospital, Dibrugarh were studied from June 2019 to May 2020. By the null hypothesis, we propose that etomidate has better haemodynamic stability over propofol at the time of anaesthetic induction. After approval by Institutional Ethic Committee $(\mathrm{H})$ and obtaining written informed consent from the patients, 80 patients were randomly divided into two groups of 40 each. After double blinding, randomization was done by opening a sealed envelope just before entry to the operation theatre.

Patients were grouped into - Group E: Etomidate group $(\mathrm{n}=40)$, Group P: Propofol group $(\mathrm{N}=40)$. Sample size justification is based upon the previous studies at $5 \%$ level of significance and power of study in $95 \%$ to detect at least $15 \%$ difference in mean arterial pressure. The minimum number of patients required to get a statistically significant number was 35 or more ${ }^{15}$. Hence, we decided to recruit 40 patients in each group considering we might encounter some dropouts. Consecutive patients satisfying the inclusion criteria were included in the study till the sample size was reached. Demographic parameters were recorded. Patients were explained about the anaesthesia technique in their own understandable language. Pre-operatively, the patients were enquired about the relevant history and general and systemic examinations along with airway assessment were done.

Anaesthesia machines, circuits were checked for proper functioning and resuscitation drugs and equipment were kept ready. The routine investigations were done, and all patients were kept for a minimum of 6 hours fasting prior to surgery. In the operation theatre before commencement of surgery, 18gauge intravenous line was secured and preloaded with $5 \mathrm{ml} / \mathrm{kg}$ Ringer's lactate. Monitors for pulse oximetry for oxygen saturation $\left(\mathrm{SpO}_{2}\right)$, electrocardiogram (ECG), end tidal carbon dioxide $\left(\mathrm{ETCO}_{2}\right)$, non-invasive blood pressure (NIBP) and Bispectral index were connected, and baseline values were noted. BIS sensor, composed of a self-adhering flexible band holding three electrodes was applied to the forehead and temple to measure the Bispectral index of the patients.

Patients were pre-medicated with the following drugs - Inj. palonosetron $0.075 \mathrm{mg}$ intravenously, inj. pantoprazole $40 \mathrm{mg}$ intravenously, inj. glycopyrrolate $0.2 \mathrm{mg}$ intravenously and inj. fentanyl $2 \mathrm{mcg} / \mathrm{kg}$ intravenously prior to surgery. All the patients were preoxygenated with $100 \%$ oxygen for 3 minutes with facemask of appropriate size. Then infusion of anaesthetic agents was started. Simple method of tossing a coin was used for randomisation to include either in Group E or Group P. Group E patients were induced with infusion etomidate at a rate of $0.05 \mathrm{mg} / \mathrm{kg} / \mathrm{min}$ and Group P patients were induced with infusion propofol at a rate of $0.5 \mathrm{mg} / \mathrm{kg}$ $/$ min. As soon as the BIS value reached 60 , the anaesthetic infusion was stopped. However, if during intubation there was an increase in the BIS reading, infusion of induction agent was restarted until no increase in BIS values was observed. Endotracheal intubation was facilitated with an appropriate size endotracheal tube with inj. vecuronium (dose of 0.1 $\mathrm{mg} / \mathrm{kg}$ ) in a single attempt less than 20 seconds. 


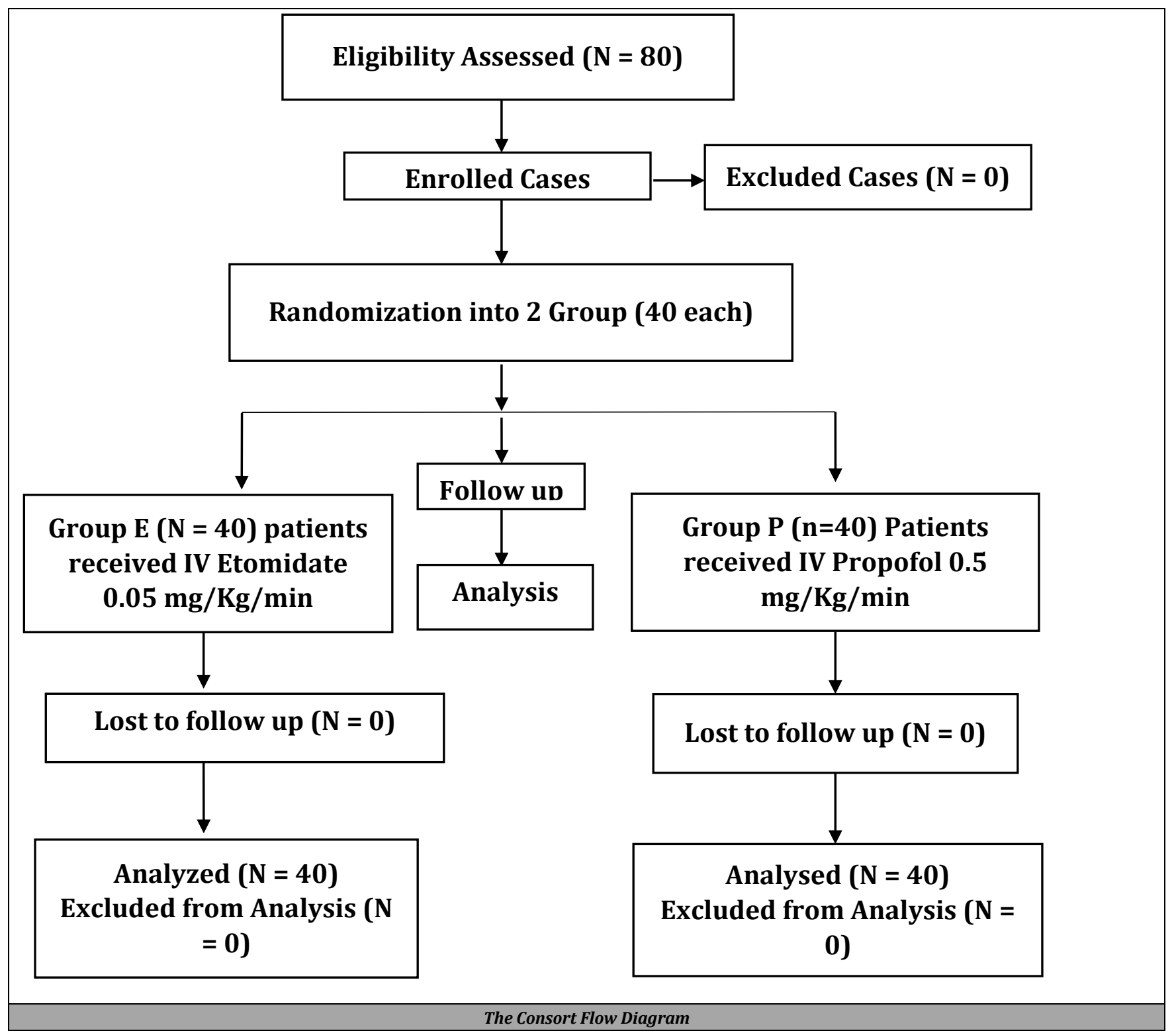

Proper placement of the endotracheal tube was confirmed by capnography and 5-point auscultation of chest. Following successful placement of the endotracheal tube, controlled ventilation was maintained with $33 \%$ oxygen and $66 \%$ nitrous oxide and sevoflurane inhalation in titrated dose. Muscle relaxation was maintained with intermittent iv vecuronium $0.02 \mathrm{mg} / \mathrm{kg}$ whenever needed. Intravenous fluid was given as Ringer's lactate and normal saline $0.9 \%$ at a rate of $4-6 \mathrm{ml} / \mathrm{kg} / \mathrm{hr}$. Anaesthesia was maintained as per institutional protocol. The hemodynamic parameters heart rate, systolic blood pressure, diastolic blood pressure, mean arterial blood pressure, oxygen saturation and end tidal carbon-dioxide $\left(\mathrm{ETCO}_{2}\right)$ were timely monitored and recorded before induction ( 0 minute or baseline) and 1, 3, 5, 7, 10 minutes after induction. Residual neuromuscular blockade was antagonized by neostigmine $0.05 \mathrm{mg} / \mathrm{kg}$ and glycopyrrolate $0.01 \mathrm{mg} / \mathrm{kg}$ iv after completion of surgery. The patients were extubated when BIS value attains 90 .

\section{Inclusion Criteria}

Included patients in this study were patients with American society of Anaesthesiologists (ASA) grade I, II, aged 18 years and above, irrespective of gender and weight and who gave informed written consent.

\section{Exclusion Criteria}

Exclusion criteria were patients not willing to give written informed consent, ASA physical status III and IV, mouth opening less than $2.5 \mathrm{~cm}$, age less than 18 years, emergency surgeries, any hypersensitivity or contraindication to etomidate or propofol, pregnant or lactating mothers, left ventricular ejection fraction less than $40 \%$, having preexisting hemodynamically unstable arrhythmias, presence of bleeding diathesis, Mallampati grade 3 and 4.

\section{Statistical Analysis}

The statistical analysis of data was performed using the computer program, Statistical package for social sciences (SPSS for Windows, version 20.0 Chicago, SSPC Inc.) and Microsoft Excel 2010. Results on continuous measurements were presented as mean \pm standard deviation and was compare using student's t-test. Discrete data was expressed as number (\%) and analysed using chi square test and Fischer 
exact test (where cell counts were $<5$ ). For all analyses, the substantial significance was fixed at $5 \%$ level (P value defaults to 0.05 ).

\section{RESULTS}

The two groups i.e., Group E (receiving etomidate) and Group $P$ (receiving propofol) were compared with regard to age, gender, height, weight and ASA grade. Etomidate group had a mean age of $41.03 \pm 10.94$ years and propofol group had a mean age of $38.28 \pm 11.98$ years. As for the gender distribution, there were 23 males and 17 females in etomidate group and 20 males and 20 females in propofol group. Mean weight of patients in etomidate group was $61.53 \pm 5.48 \mathrm{~kg}$ and that of propofol group was $62.63 \pm 5.83 \mathrm{~kg}$. Mean height of the etomidate group was $161.85 \pm 5.66 \mathrm{~cm}$ and that of propofol group was $162.06 \pm 6.86 \mathrm{~cm}$. There were 23 patients of ASA I and 17 patients of Asa II in the etomidate group and 25 patients of ASA I and 25 patients of ASA II in the propofol group. The demographic profile thus showed that these values had no statistical significance with $P$ value greater than 0.05 . It was observed that starting from 3 minutes of induction up to 10 minutes as shown in the Figure 1, there was a fall in heart rate from baseline in the propofol group. The baseline value of mean heart rate in this group was found to be $79.70 \pm 4.61$ which dropped to $75.10 \pm 3.88$ at 3 minutes and further dropped to $67.95 \pm 2.89$ at 10 minutes. However, there was a rise in heart rate in etomidate group from the baseline within the same period.

The baseline value of mean heart rate in this group was $78.48 \pm 5.63$ which rose to $83.80 \pm 4.10$ at 3 minutes and then further increased to $88.28 \pm 3.52$ at 10 minutes. This difference in mean heart rate between the two groups at different time interval of induction (from 3 minutes to 10 minutes) was found to be statistically significant $(\mathrm{P}<0.001)$.

Figure 2 shows that when compared with the baseline mean systolic blood pressure values, there was a greater fall in the propofol group than that in the etomidate group starting from 1 minute of induction up to 10 minutes. In the propofol group, the mean systolic blood pressure at baseline, 1 minute and 10 minutes were found to be $125.95 \pm 9.17,113.13 \pm 9.11$ and $98.98 \pm 3.35$ respectively. Similarly, in the etomidate group, the mean systolic blood pressure at baseline,1 minute and 10 minutes were $126.65 \pm 7.98,123.60 \pm 7.14$ and 117.45 \pm 7.01 respectively. The difference between the two groups at various time intervals from 1 minute of induction to 10 minutes was statistically significant ( $P$ value $<0.001$ ).

Figure 3 shows that following induction after 3 minutes to 10 minutes, a change in diastolic pressure was more in propofol group compared to etomidate group with respect to the pre-induction base line values. The mean diastolic blood pressure at baseline, 3 minutes and 10 minutes in the propofol group were $82.75 \pm 6.13,68.90 \pm 5.33$ and $61.10 \pm 3.85$ respectively. Again, the mean diastolic blood pressure in the etomidate group at baseline, 3 minutes and 10 minutes were $84.10 \pm 5.75,76.60 \pm 5.50$ and $72.25 \pm 4.94$ respectively. The difference was statistically significant between the two groups at various time intervals from 3 minutes to 10 minutes ( $P$ value $<0.001$ ).
Figure 4 shows that fall in mean arterial pressure was greater in the propofol group in comparison to the etomidate group. The mean of the mean arterial pressure in the propofol group at baseline, 1 minute and 10 minutes were $97.18 \pm 6.72$, $88.73 \pm 6.28$ and $73.70 \pm 3.10$ respectively. The mean of the mean arterial pressure in the etomidate group at baseline, 1 minute and 10 minutes were $98.30 \pm 6.09,93.78 \pm 5.50$ and $87.35 \pm 5.26$ respectively.

Now this fall was seen from 1 minute of induction up to 10 minutes which is statistically significant ( $P$ value $<0.001$ ). The mean value of Bispectral index was compared between the etomidate group and propofol group. In the propofol group, the mean BIS value at baseline and 10 minutes were found to be $98.13 \pm 1.22$ and $59.25 \pm 2.24$ respectively. In the etomidate group, the mean BIS value at baseline and 10 minutes were found to be $98.58 \pm 1.03$ and $59.00 \pm 1.75$ respectively. BIS value in the two groups was found to have no statistical significance at all-time intervals. The mean oxygen saturation $\left(\mathrm{SPO}_{2}\right)$ was compared between the two groups at various time intervals.

The mean oxygen saturation in the propofol group at baseline was $98.73 \pm 0.96$ and after 10 minutes was $98.60 \pm$ 0.84 . The baseline value of mean oxygen saturation in the etomidate group was $98.78 \pm 0.86$ and the value at 10 minutes was found to be $98.80 \pm 0.76$. This shows that there was no statistically significant difference in the mean oxygen saturation values between the two groups. End tidal carbondioxide $\left(\mathrm{EtCO}_{2}\right)$ was also compared between the two groups from baseline up to 10 minutes of induction. The mean end tidal carbon-dioxide baseline and 10 minutes values in the propofol group were found to be $39.60 \pm 2.06$ and $39.28 \pm 2.31$ respectively and in the etomidate group the values were 39.80 \pm 2.10 and $39.88 \pm 2.33$ respectively. The difference of which was statistically not significant between the two groups.

\begin{tabular}{|cccccc|}
\hline \multirow{2}{*}{ Time } & \multicolumn{2}{c|}{ Group-E } & \multicolumn{2}{c|}{ Group-P } & \multirow{2}{*}{ P Value* } \\
Baseline (0 min) & 78.48 & 5.63 & 79.70 & 4.61 & 0.291 \\
At 1 min & 80.13 & 5.35 & 80.88 & 4.30 & 0.492 \\
At 3 mins & 83.80 & 4.10 & 75.10 & 3.88 & $<0.001$ \\
At 5 mins & 85.50 & 4.05 & 71.60 & 2.78 & $<0.001$ \\
At 7 mins & 90.08 & 3.10 & 72.15 & 3.90 & $<0.001$ \\
At 10 mins & 88.28 & 3.52 & 67.95 & 2.89 & $<0.001$ \\
\hline & Table 1. Heart Rate (Beats/Min) \\
\hline 'Student's t-test
\end{tabular}

\begin{tabular}{|c|c|c|c|c|c|}
\hline \multirow{2}{*}{ Time } & \multicolumn{2}{|c|}{ Group-E } & \multicolumn{2}{|c|}{ Group-P } & \multirow{2}{*}{ P Value ${ }^{*}$} \\
\hline & Mean & S.D & Mean & S.D. & \\
\hline Baseline (0 min) & 126.65 & 7.9 & 125.95 & 9.17 & 0.7168 \\
\hline At 1 mins & 123.60 & 7.14 & 113.13 & 9.11 & $<0.001$ \\
\hline At 3 mins & 121.93 & 7.55 & 100.60 & 7.23 & $<0.001$ \\
\hline At 5 mins & 117.88 & 7.13 & 96.33 & 5.70 & $<0.001$ \\
\hline At 7 mins & 116.90 & 6.34 & 93.23 & 4.14 & $<0.001$ \\
\hline At $10 \mathrm{mins}$ & 117.45 & 7.01 & 98.98 & 3.35 & $<0.001$ \\
\hline \multicolumn{6}{|c|}{ Table 2. Systolic Blood Pressure } \\
\hline -test & & & & & \\
\hline
\end{tabular}

\begin{tabular}{|cccccc|}
\hline Time & Group-E & \multicolumn{2}{c|}{ Group-p } & \multirow{2}{*}{ P Value $^{*}$} \\
Bean & S.D. & Mean & S.D. & \\
At 1 mins & 79.08 & 5.13 & 76.53 & 5.45 & 0.034 \\
At 3 mins & 76.60 & 5.50 & 68.90 & 5.33 & $<0.001$ \\
At 5 mins & 73.98 & 5.31 & 64.65 & 5.59 & $<0.001$ \\
At 7 mins & 73.35 & 5.91 & 57.55 & 4.85 & $<0.001$ \\
At 10 mins & 72.25 & 4.94 & 61.10 & 3.85 & $<0.001$ \\
\hline \multicolumn{7}{|c}{ Table 3. Diastolic Blood Pressure } \\
\hline *Student's t-Test
\end{tabular}



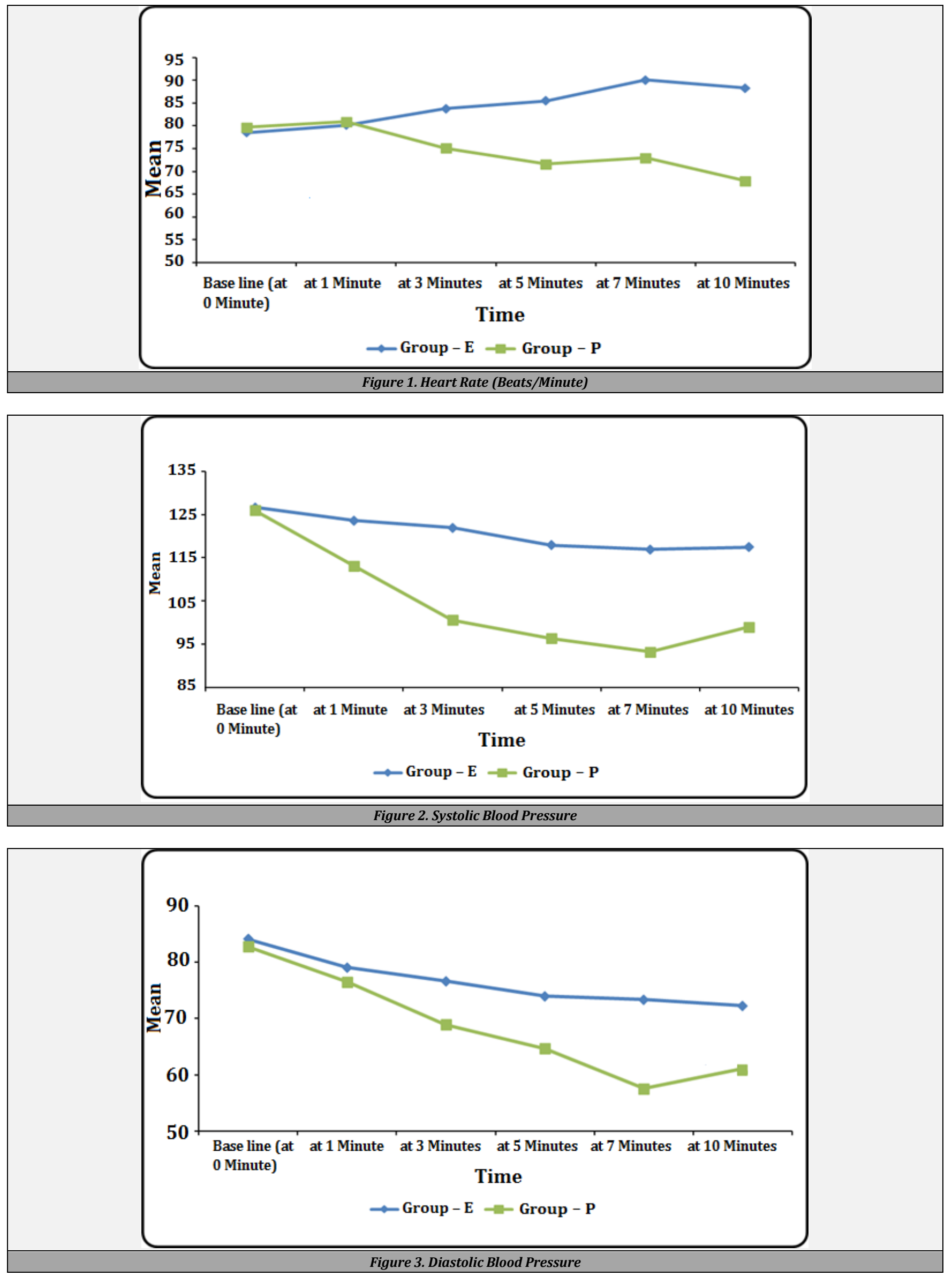


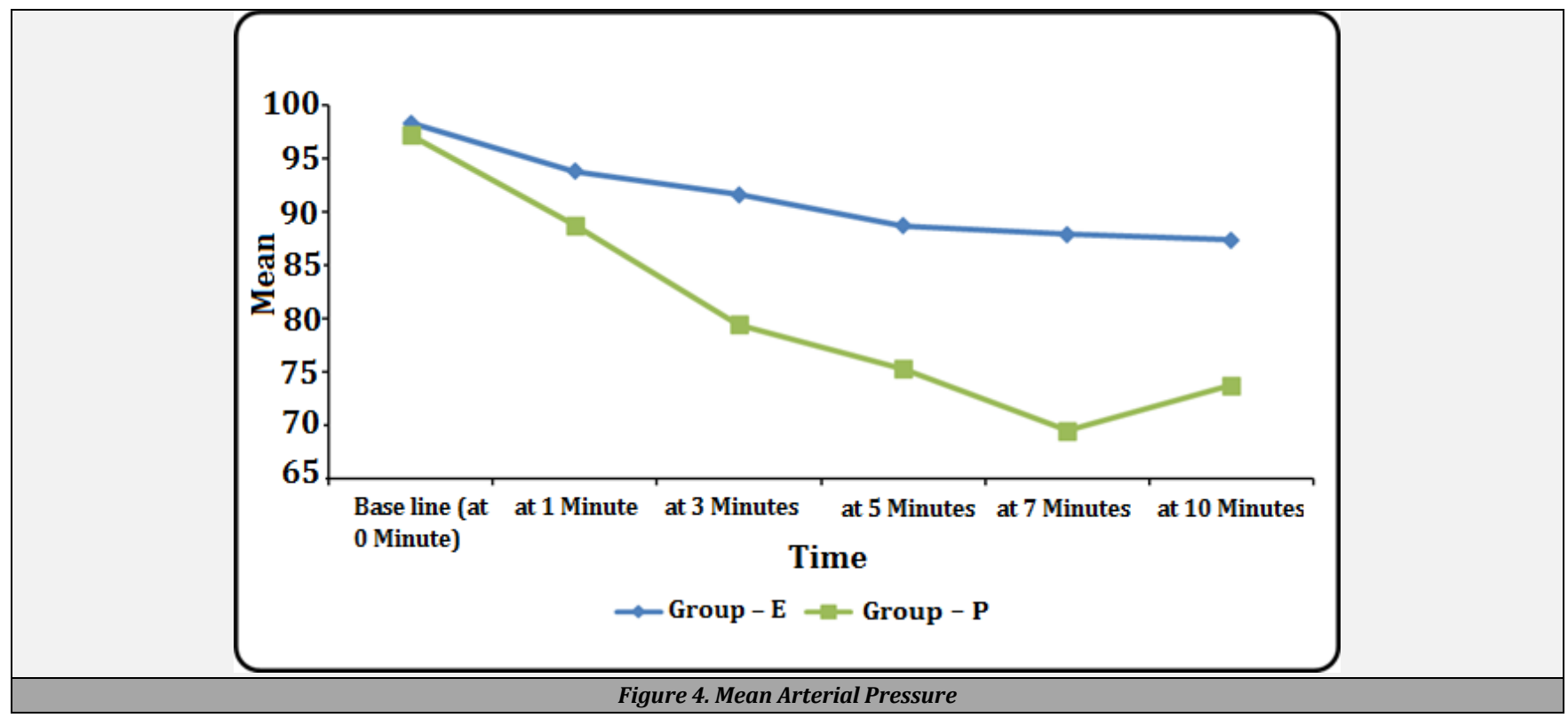

\section{DISCUSSION}

Inducing agents or drugs are those substances that cause rapid loss of consciousness when they are given in the appropriate dose. These are given before the drugs which are used for maintenance of anaesthesia. They can also be given as a single drug for procedures of shorter duration or as an agent to provide conscious sedation during the procedures which are undertaken under local anaesthesia. Quick and rapid induction and haemodynamic stability with minimum side effects are the most important and desired characteristics while taking into account an ideal induction agent. So various studies have been conducted from time to time to understand and compare the haemodynamic response with the use of various induction agents while induction of general anaesthesia. Both etomidate and propofol which are ultra-short acting sedative agents are widely used as induction agents. Both are non-barbiturate sedative hypnotic drug which act via modulation of $\mathrm{GABA}_{\mathrm{A}}$ receptors ${ }^{10}$ and have similar onset and duration of action. However, both of them differ regarding their action on cardiovascular system. Mild to moderate degree of hemodynamic variations are associated with induction of anaesthesia which depend on many factors. There are very few studies and very little data available for comparing the hemodynamic effect of propofol with that of etomidate under Bispectral index while inducing general anaesthesia as a technique of objective monitoring for the depth of anaesthesia in this part of our country. Taking into account this difference in their mode of action on the cardiovascular system the present study was undertaken in our tertiary care institute.

Awareness can occur during the conduction of general anaesthesia. Patient may develop even explicit recall of entire event while under anaesthesia. This awareness can lead to post-traumatic stress disorder. ${ }^{11}$ Suggestions have been postulated that cerebral monitoring can be used to determine the depth of anaesthesia, prevent awareness, and facilitate early recovery. Cerebral monitoring also optimizes the drug delivery to each patient. ${ }^{12}$
In this present study, we compared the hemodynamic response during induction of general anaesthesia with etomidate and with propofol under bispectral index guidance.

There are a number of early studies conducted on this topic which bear a similar result to the present study. In more recent years, Anil K. Pandey and colleagues ${ }^{13}$ in 2012, derived a conclusion in their study that systolic blood pressure and diastolic blood pressure were significantly different between propofol and etomidate groups at 5 minutes after induction. And were statistically significantly lower in propofol group which is similar to findings in our study where both systolic and diastolic blood pressures were lower in propofol group and the difference in between the groups was statistically significant with $\mathrm{P}$ value $<0.05$ indicating that etomidate is associated with more stable haemodynamics on induction of anaesthesia. Recently in 2015 Shivaprakash Shivanna et al. ${ }^{14}$ performed a comparative study of hemodynamic effects of propofol and etomidate as an induction agent in coronary artery surgery. They found that after induction, the changes in the heart rate in both etomidate and propofol were significant. Also in 2015, Supriya Agarwal et al.15 performed a comparative study between etomidate and propofol in hundred patients under general anaesthesia. They found that compared to propofol, patients induced with etomidate showed insignificant changes in heart rate. Etomidate does not exert any effect on sympathetic nervous system and baroreceptor function due to which it is believed to have exceptional hemodynamic stability and preserve this stable state during anaesthesia as well. In the year 2012 Moller Petrun and M. Kamenik ${ }^{16}$ and in the year 2017 Purnima Shivanna ${ }^{17}$ performed similar studies comparing the hemodynamic effects of etomidate and propofol during induction of anaesthesia under BIS guidance. These studies concluded that even the reduced doses with the BIS guided protocol, propofol often causes significant hypotension in comparison to that of etomidate. In 2006, J.W.Johansen ${ }^{18}$ conducted a study on bispectral index monitoring and concluded that BIS is one of the monitoring methods that is validated for measuring the depth of anaesthesia. In the present-day study, the rationale of infusion technique of induction agents to BIS 60 was to decrease the total dose of 
induction agents with subsequent decrease in hemodynamic attenuation.

It is important to note that propofol infusion syndrome is a rare syndrome that occurs in patients who are on prolonged propofol infusion for sedation. It occurs when patients receive (> $75 \mathrm{mcg} / \mathrm{kg} /$ minute) of propofol for longer than 24 hours. It is associated with cardiac failure, rhabdomyolysis, metabolic acidosis, and kidney failure. Early recognition is important and discontinuation of propofol infusion decreases morbidity and mortality.

\section{CONCLUSIONS}

In the results of the present study, propofol produced more hemodynamic instability with hypotension and bradycardia than etomidate, despite titration of these anaesthetic agents to an appropriate anaesthesia depth under Bispectral index guidance induction. In conclusion, we can agree with our proposed null hypothesis that etomidate as an inducing agent has better haemodynamic stability over propofol at the time of anaesthetic induction. Etomidate is a better option in patients who are prone to hemodynamic fluctuation at induction like uncontrolled hypertension and septic patients. To establish this, more studies with greater number of representative samples are required.

Data sharing statement provided by the authors is available with the full text of this article at jemds.com.

Financial or other competing interests: None.

Disclosure forms provided by the authors are available with the full text of this article at jemds.com.

\section{REFERENCES}

[1] Singh R, Choudhury M, Kapoor PM, et al. A randomized trial of anesthetic induction agents in patients with coronary artery disease and left ventricular dysfunction. Ann Card Anaesth 2010;13(3):217-23.

[2] Fahy LT, Mourik GA, Utting JE. A comparison of the induction characteristics of thiopentone and propofol (2,6-di-isopropyl phenol). Anaesthesia 1985;40(10):93944 .

[3] Gold MI, Abraham EC, Herrington C. A controlled investigation of propofol, thiopentone and methohexitone. Can J Anaesth 1987;34(5):478-83.

[4] McKeating K, Bali IM, Dundee JW. The effects of thiopentone and propofol on upper airway integrity. Anaesthesia 1988;43(8):638-40.
[5] Miller R, Cohen $\mathrm{N}$, Erikson $\mathrm{L}$, et al. Intravenous anesthetics. In: Vuyk J, Sitsen E, Reekers M, eds. Miller's Anesthesia. Eight. Philadelphia: Elsevier/Saunders 2015: p. 831.

[6] Forman SA. Clinical and molecular pharmacology of etomidate. Anesthesiology 2011;114(3):695-707.

[7] Sinha PK, Koshy T. Monitoring devices for measuring the depth of anaesthesia-an overview. Ind J Anaesth 2007;51(5):365-81.

[8] Bruhn J, Myles PS, Sneyd R, et al. Depth of anaesthesia monitoring: what's available, what's validated and what's next? Br J Anaesth 2006;97(1):85-94.

[9] Johansen JW, Sebel PS. Development and clinical application electroencephalographic bispectrum monitoring. Anesthesiology 2000;93(5):1336-44.

[10] Drexler B, Jurd R, Rudolph U, et al. Distinct actions of etomidate and propofol at beta 3-containing gammaaminobutyric acid type a receptors. Neuropharmacology 2009;57(4):446-55.

[11] Osterman JE, Hopper J, Haren WJ, et al. Awarness under anaesthesia and development of posttraumatic stress disorder. Gen Hosp Psychiatry 2001;23(4):198-204.

[12] Rowsow C, Manberg PJ. Bispectral index monitoring. Anesthesiol Clin North Am 2001;19(4):947-66.

[13] Pandey AK, Makhija N, Chauhan S, et al. The effects of etomidate and propofol induction on hemodynamic and endocrine response in patients undergoing coronary artery bypass graft surgery on cardiopulmonary bypass. World J Cardiovasc Surg 2012;2(3):48-52.

[14] Shivanna S, Priye S, Jagannath S, et al. A comparative study of hemodynamic effects of propofol and etomidate as an induction agent in coronary artery surgery. J Evol Med Dent Sci 2015;4(4):598-607.

[15] Aggarwal S, Goyal VK, Chaturvedi SK, et al. A comparative study between propofol and etomidate in patients under general anesthesia. Brazilian J Anesthesiol 2015;66(3):237-41.

[16] Petrun AM, Kamenik M. Bispectral index-guided induction of general anaesthesia in patients undergoing major abdominal surgery using propofol or etomidate: a double-blind, randomized, clinical trial. Br J Anaesth 2012;110(3):388-96

[17] Shivanna P. Comparison of induction characteristics and hemodynamic parameters of propofol versus etomidate in patients undergoing surgeries under general anaesthesia, a bispectral index guided study. Int J Innov Res Med Sci 2017;02(11):1458-67.

[18] Johansen JW. Update on bispectral index monitoring. Best Pract Res Clin Anaesthesiol 2006;20(1):81-99. 